\title{
Sudden cardiac death in a woman with clinical evidence of coronary vasospastic disease and myocardial stunning. A necrospy insight into the etiology
}

\author{
Carlo Caiati", Mario Erminio Lepera, Andrea Marzullo and Stefano Favale \\ Unit of Cardiovascular Diseases, Department of Emergency and Organ Transplantation, University of Bari, Italy
}

\begin{abstract}
This case shed some light on the etiology of severe coronary vasospastic disease. A 54 years old lady with metabolic syndrome had a terminal ventricular fibrillation after an episode of acute ischemia caused by a coronary spasm. At the autopsy study an inflammatory perivascular and mainly perineural infiltration of the autonomic fibres of the cardiac nerves, confirmed at immunohistochemistry, could suggest a potential susceptibility of the nervous fibres to evoke an intense coronary vasospastic response as a consequence of non-specific events.
\end{abstract}

\section{Background}

The etiology of vasospatic angina is not well known [1]. Coronary endodothelium and autonomic nerves dysfunction have been indicated as a possible mechanism of coronary vasospasm but these studies have had little clinical impact as no causes of this dysfunction if any, has been demonstrated [2-7].

\section{Objective}

We presented a case of clinical vasospatic angina associated with myocardial stunning, unfortunately ended with the sudden cardiac death of the patient whose subsequent necropsy examination revealed inflammatory infiltrate of the autonomic cardiac nerve, thus identifying a probable etiologic factor of the coronary vasospastic disease.

\section{Methods and findings}

A 52 year old woman was admitted to the emergency department 3 hours after the onset of chest pain. The patient was a mild obese black woman with a history of dyslipidemia, hypertension, type 2 diabetes mellitus, hiatal hernia and recurrent chest pain. A coronary angiography performed 2 years earlier had demonstrated the absence of significant coronary stenosis. The physical was unremarkable. The first electrocardiogram showed left bundle branch block, already present at a previous evaluation, but with deep negative $\mathrm{T}$ waves $(>5 \mathrm{~mm})$ concordant to QRS associated with mild ST elevation $(3 \mathrm{~mm}$ ) in leads V2-V3. Troponine I peak was at $0.43 \mathrm{ng} / \mathrm{ml}$. The echocardiography demonstrated a left ventricle (LV) with a mid-septal akinesia and apical dyskinesia and with an ejection fraction of $50 \%$. Such LV diskinesia completely reverted to normal 1 week after the recovery. The angiography confirmed the 2 years earlier angiographic findings. During the recovery the patient complained recurrent chest pain and such episodes were scarcely ameliorated by calcium channel blockers and nitrates. About 16 hours after the discharge, early in the morning at the awakening, as reported by relatives, the patient developed intense chest pain terminating after 20 minutes with a rapid resolution followed by syncope due to irreversible cardiac arrest. Autopsy was performed to clarify the cause of death.

Holter monitoring during the lethal syncope. In the first 16 hours the recording was unremarkable. At 4:08 a.m. the ST segment rose to a peak of $9 \mathrm{~mm}$ above the isoelectric line within 12 minutes and remained so elevated for a further 13 minutes, then dropped to $2 \mathrm{~mm}$ above the isoelectric line within 2 minutes. Repetitive ventricular ectopic beats started, leading immediately to ventricular fibrillation.

Autopsy findings. At autopsy, the heart (330 g of weight) showed a mild left ventricular hypertrophy and a marked but non occlusive coronarosclerosis. Histology showed myocardial signs of a recent acute ischemia and ventricular fibrillation and at the level epicardial layer of the heart a mild infiltration composed of mononuclear cells with a perivascular and perineural pattern of distribution. (Figure 1) These cells resulted positive to the immunostain for $\mathrm{T}$ lymphocyte marker $\mathrm{CD}$ 3. No expression for B lymphocyte and macrophage antigens (CD 20 and CD 68 respectively) were observed.

\section{Discussion}

The clinical history clearly depicts a malignant coronary vasospastic disease and the post mortem histology identifies an inflammatory perivascular and mainly perineural infiltration of the autonomic fibres of the cardiac nerves confirmed at immunohistochemistry that could suggest a potential susceptibility of the nervous fibres to evoke an intense coronary vasospastic response as a consequence of non-specific events. Several observations suggests that the autonomic nerves dysfunction is important in the development of coronary vasospasm [2-7] but they do not give any idea on why such an autonomic imbalance, if any, does occur.

Correspondence to: Carlo Caiati, Unità Operativa di Cardiologia Universitaria Policlinico di Bari, Piazza G. Cesare, Italy, Tel: +39-080-5592750; Fax: +39-0805478796; E-mail: carlo.caiati@uniba.it

Received: November 07, 2016; Accepted: December 05, 2016; Published: December 08, 2016 


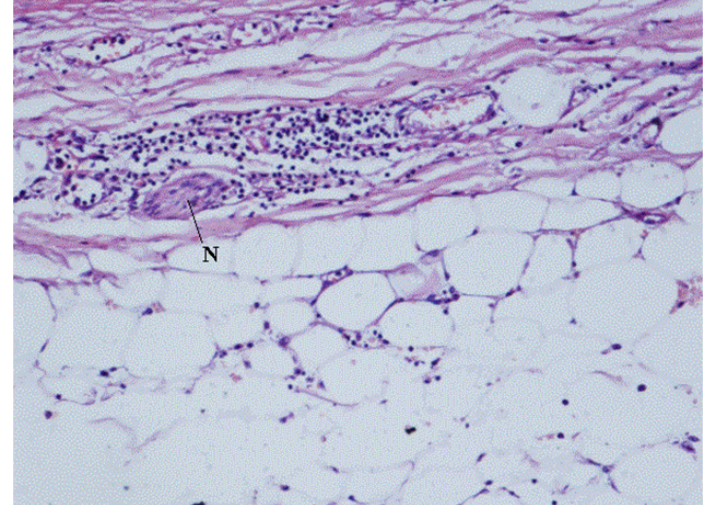

Figure 1. A perivascular lympho-mononuclear infiltration in the epicardial fatty tissue embracing a small nerve (N) (Ematoxylin-Eosin; $200 \mathrm{X}$ original magnification).

Our study demonstrated for the first time a concrete histopathologic alteration (perineural inflammation of the cardiac nerves) that may represent the pathologic substrate subtended to an autonomic imbalance potentially inducing a coronary vasospasm. This finding concurs and corroborate in terms of hystology other studies of the literature that document low grade chronic inflammation by means of humoral markers (P-Selection adhesion molecules, elevated HESR) in patients with coronary spasm. As far as we know, all the histopathological studies reported in the literature regarding patients with coronary vasospatic disease, were performed on endomyocardial biopsies and documented a scant interstitial lympho-histiocite infiltration, mild fibrosis and occasional contraction band. Endothelial dysfunction associated or not to a frank obstructive plaque (in our case there was a a subcclussive plaque in the left anterior descending coronary artery) has a common occurrence and does not cause clinically significant spasm, thus other factors are concomitantly needed to cause coronary spasm.

Why inflammation of the autonomic nerve can occur is unknown. However our patient was mild obese and diabetic. This metabolic condition favors silent inflammation in the tissue thanks mainly to hyper-insulinemia $[8,9]$ triggered to insulina resistance. Thus it can be hypothesized that a control of both obesity and hyperinsulinemia through life style changes [10] may have a curative impact in the long term on the vasospatic disease by reducing silent chronic inflammation. Further studies are needed to test this hypothesis in patients with coronary vasospasm.

\section{References}

1. Yasue H, Nakagawa H, Itoh T, Harada E, Mizuno Y (2008) Coronary artery spasm-clinical features, diagnosis, pathogenesis, and treatment. J Cardiol 51: 2-17. [Crossref]

2. Lacy CR, Contrada RJ, Robbins ML, Tannenbaum AK, Moreyra AE, et al. (1995) Coronary vasoconstriction induced by mental stress (simulated public speaking). Am J Cardiol 75: 503-505. [Crossref]

3. Sakata K, Yoshida H, Hoshino T, Kurata C (1996) Sympathetic nerve activity in the spasm-induced coronary artery region is associated with disease activity of vasospastic angina. J Am Coll Cardiol 28: 460-464. [Crossref]

4. Sakata K, Shirotani M, Yoshida H, Kurata C (1997) Iodine-123 metaiodobenzylguanidine cardiac imaging to identify and localize vasospastic angina without significant coronary artery narrowing. J Am Coll Cardiol 30:370-6. [Crossref]

5. Sakata K, Miura F, Sugino H, Saegusa T, Shirotani M, et al. (1997) Assessment of regional sympathetic nerve activity in vasospastic angina: analysis of iodine 123-labeled metaiodobenzylguanidine scintigraphy. Am Heart J 133: 484-489. [Crossref]

6. Takano H, Nakamura T, Satou T, Umetani K, Watanabe A, et al. (1995) Regional myocardial sympathetic dysinnervation in patients with coronary vasospasm. $\mathrm{Am} \mathrm{J}$ Cardiol 75: 324-329. [Crossref]

7. Wittstein IS, Thiemann DR, Lima JA, Baughman KL, Schulman SP, et al. (2005) Neurohumoral features of myocardial stunning due to sudden emotional stress. $N$ Engl J Med 352: 539-548. [Crossref]

8. Després JP, Lamarche B, Mauriège P, Cantin B, Lupien PJ, et al. (1996) Risk factors for ischaemic heart disease: is it time to measure insulin? Eur Heart $J$ 17: 1453-1454. [Crossref]

9. Després JP, Lamarche B, Mauriège P, Cantin B, Dagenais GR, et al. (1996) Hyperinsulinemia as an independent risk factor for ischemic heart disease. $N$ Engl $J$ Med 334: 952-957. [Crossref]

10. Sdringola S, Nakagawa K, Nakagawa Y, Yusuf SW, Boccalandro F, et al. (2003) Combined intense lifestyle and pharmacologic lipid treatment further reduce coronary events and myocardial perfusion abnormalities compared with usual-care cholesterollowering drugs in coronary artery disease. J Am Coll Cardiol 41: 263-272. [Crossref]

Copyright: (C2016 Caiati C. This is an open-access article distributed under the terms of the Creative Commons Attribution License, which permits unrestricted use, distribution, and reproduction in any medium, provided the original author and source are credited. 